\title{
Infantile Apnea, AE
}

National Cancer Institute

\section{Source}

National Cancer Institute. Infantile Apnea, AE. NCI Thesaurus. Code C154938.

An adverse event in a newborn characterized by cessation of air flow. 